\title{
The Effects of Task Characteristics on L2 Learners' Production of Complex, Accurate, and Fluent Oral Language
}

Mansoor Fahim

Faculty of Persian Literature and Foreign Languages

Allameh Tabataba’i University, Tehran, Iran

E-mail: drfahim@yahoo.com

Saeed Nourzadeh (Corresponding author)

Faculty of Persian Literature and Foreign Languages

Allameh Tabataba’i University, Tehran, Iran

E-mail: saeednourzadeh@yahoo.com

\section{Jalil Fat’hi}

Faculty of Persian Literature and Foreign Languages

Allameh Tabataba’i University, Tehran, Iran

E-mail: jfathi13@yahoo.com

Received: October 28, 2011 Accepted: November 24, 2011 Published: December 31, 2011 doi:10.5296/ije.v3i2.1281ＵRL: http://dx.doi.org/10.5296/ije.v3i2.1281 


\begin{abstract}
One recent fruitful development in the area of second language (L2) acquisition has been Task-Based Language Teaching (TBLT). Consequently, L2 researchers have paid particular attention to the role that the employment of tasks plays in the development of interlanguage competence. Of particular interest have been the factors that increase the difficulty with which L2 learners perform and process pedagogical tasks. The present paper is an attempt to present a review of factors that have been found to affect learners' task performance, along with studies that have provided empirical evidence as to how these factors increase the cognitive demands of learners' task performance. Understanding the functioning of these task performance factors are of paramount importance to language teachers who are to follow TBLT principles since such understanding can provide them with sequencing criteria that can guide the order in which they employ tasks in their everyday teaching efforts.
\end{abstract}

Keywords: Task-Based language teaching, Interlanguage competence, Task difficulty, Pedagogical tasks, Task performance, Cognitive demands, Sequencing criteria 


\section{Introduction}

As a recent development in the field of second language (L2) teaching, Task-Based Language Teaching (TBLT) has inspired a lot of pedagogical innovations and theoretical investigations among L2 teachers and researchers. Today, language teachers look upon TBLT as a fruitful approach to L2 instruction that has the potentiality to provide them with new insights into the most effective ways an L2 can be taught. Similarly, L2 researchers have begun a research agenda to test the frequent claims that are made in support of TBLT. They have undertaken experiments to investigate whether the superiority of TBLT over more traditional approaches to language teaching and learning can be supported by research findings, what are learners' attitudes towards task-based pedagogy, how TBLT can be employed to improve learners' language skills (i.e., listening, speaking, reading, and writing), what cognitive processes are involved in task performance, etc.

Of these research topics, the most flourishing one has centered on the question of what factors increase the difficulty with which $\mathrm{L} 2$ learners perform and process pedagogical tasks. Aware of far-reaching implications of TBLT for language classrooms, we intend in this paper to present a review of factors that have been found to affect learners' task performance, along with studies that have provided empirical evidence as to how these factors increase the cognitive demands of learners' task performance. Understanding the functioning of these task performance factors are of paramount importance to language teachers who are to follow TBLT principles since such understanding can provide them with sequencing criteria that can guide the order in which they employ tasks in their everyday teaching efforts.

There exists one point in order before we embark on explaining task-performance factors targeted in the present review study. The point relates to the fact that most of investigations on task performance factors have been carried out with reference to Skehan's (1996a, 1996b) model of linguistic performance which states that linguistic performance consists of three aspects of complexity, accuracy, and fluency. In other words, researchers have addressed the question of whether a particular task performance factor (e.g., time planning) enhances the three aspects of linguistic performance. These three aspects of linguistic performance will be explained in short in the next section.

\section{Linguistic Complexity, Accuracy, and Fluency}

Almost all studies of task difficulty factors have investigated the role of these factors in learners' task performance with respect to three aspects of linguistic performance; i.e., complexity, accuracy, and fluency. Skehan defines these three aspects of linguistic performance as the following:

- Complexity: the elaboration or ambition of the language that is produced (1996b, p. 22)

- Accuracy: a learner's capacity to handle whatever level of interlanguage complexity s/he has currently attained (1996a, p. 46)

- Fluency: the learner's capacity to produce language in real time without undue pausing and hesitation (1996b, p. 22) 
An attempt to translate these aspects of linguistic performance into more tangible terms has been undertaken by Skehan and Foster (1999). Skehan and Foster (ibid., pp. 96-97) define linguistic complexity, accuracy and fluency as the following:

- Complexity: the capacity to use more advanced language, with the possibility that such language may not be controlled so effectively. This may also involve a greater willingness to take risks, and use fewer controlled language subsystems. This area is also taken to correlate with a greater likelihood of restructuring, that is, change and development in the interlanguage system.

- Accuracy: the ability to avoid error in performance, possibly reflecting higher levels of control in the language, as well as a conservative orientation, that is, avoidance of challenging structures that might provoke error.

- Fluency: the capacity to use language in real time, to emphasize meanings, possibly drawing on more lexicalized systems.

What is interesting with these three aspects of linguistic performance is that, with respect to complex L2 tasks, there is a trade-off between different aspects of performance in that attention to one aspect means the detriment of the other aspects. This can be explained by information processing theories which claim that human cognitive processing resources are limited in nature and, thus, cannot process all aspects of tasks at the same time (Anderson, 1995). This has lead TBLT researchers to find out what factors contribute to this trade-off and what steps can be taken so that learners' attentional resources can be optimally devoted to different aspects of linguistic performance. A review of these factors and steps is presented in the rest of the present paper.

\section{Time Planning}

One common belief among researchers working in the area of TBLT is that learners' performance on a pedagogical task will probably be enhanced if they are allowed to plan some aspects of the task before actual task performance. Abundant positive evidence on this hypothesis has been found in the SLA literature (Crookes, 1989; Ellis, 1987; Foster \& Skehan, 1996; Ortega, 1999; Skehan \& Foster, 1997; Yuan \& Ellis, 2003, to name a few). For instance, Yuan and Ellis (2003) had three groups of research participants perform a task in which the participants were required to narrate a story orally immediately after looking through a set of pictures for a very short time (0.5 minute). The participants in the first group (i.e., No Planning group) were asked to narrate the story within a limited time (5 minutes), immediately after sighting the pictures. The participants in the second group (i.e., On-line Planning group) performed the task in the same way as those in the No Planning group, with the difference that they were given unlimited time to narrate the story. Finally, the participants in the third group (i.e., Pre-task-Planning Group) were given 10 minutes to plan their performance on the task before they get involved in it. 
Yuan and Ellis (ibid.) operationalized linguistic complexity as syntactical complexity, syntactical variety, and lexical variety; linguistic accuracy as the number of error-free clauses and error-free verb forms; and linguistic fluency as the number of syllables per minute. The results of the study showed that on-line planning resulted in both greater grammatical complexity and accuracy whereas pre-task planning only improved the participants' grammatical complexity. Further, the participants' fluency and lexical variety remained the same after both types of planning. Based on these results, Yuan and Ellis (ibid.) claim that letting learners plan their task performance enhances their grammatical complexity, irrespective of what the type of planning is (i.e., whether pre-task planning or on-line planning). Further, on-line planning lets learners access their L2 grammatical knowledge, a situation resulting in more accurate sentences when performing a task. Finally, Yuan and Ellis (ibid.) attribute the ineffectiveness of pre-task time planning for linguistic fluency found in their study to the time pressure under which the participants in the Pre-Task Planning Group were required to perform the task.

On the other hand, Ortega (1999) opens a new venue into the role that pre-task planning has in interlanguage development. According to her, pre-task planning, by decreasing the load on cognitive resources during task performance, lets the learner to devote his/her attention "to formal aspects of the code as they relate to the task, and opportunities for making form-function connections, noticing the gap , and so forth are enhanced” (p. 138). To put it in simple terms, planning provides learners not only with opportunities to enhance their performance of a task, but also with a context in which they can focus their attention on new structures, resulting in the development of their interlanguage competence.

The above studies having been mentioned, it should also be pointed out that the effects of time planning on learners' performance on pedagogical tasks are not monolithic. In fact, there are a range of variables that mediate the effects of time planning on task performance. For instance, Kawauchi (2005) proposes that such effects have an interaction with learners' second language proficiency in that time planning are effective in low or intermediate language learners' task performance, but not in advanced learners' performance. Other individual differences that have been found to have an interaction with the effects of time planning on learners' task performance include working memory (Guara-Tavares, 2008, as cited in Ellis, 2009) and learners' attitudes towards planning (Tajima, 2003, as cited in Ellis, 2009). In addition to these learner variables, there are a number of task design factors (e.g., participatory structure and task complexity) that are hypothesized to have an interaction with the effects of time planning on task performance (Ellis, 2009). The effects of the interaction among time planning, individual differences, and task design on task performance has been schematically shown in the following figure (from Ellis, 2009, p. 504). 


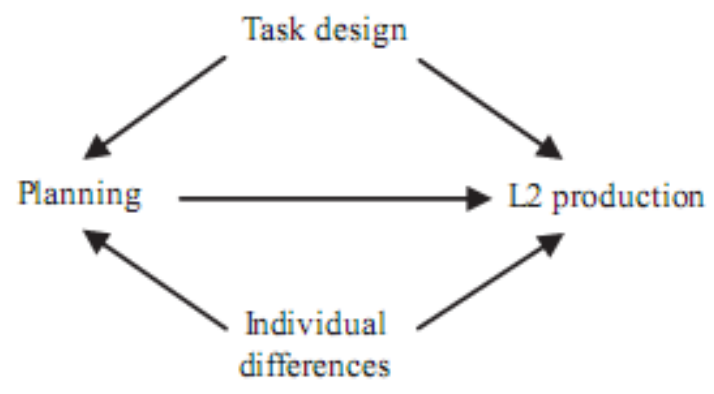

Figure 1. A framework for investigating the role of planning in task-based production

The findings of studies on time planning are also pedagogically significant since they provide answers to the question of "whether or not to allow students time to plan and, if so, what kind of planning and for what length of time” (Ellis, 2009, p. 474).

\section{Task Repetition}

In this paper, the effects of task repetition/rehearsal on task performance are discussed as a time factors since, as Ellis (2009) contends, "performance of a task at one time can be seen as providing planning for performance of the same task at a second [or a later] time” (p. 476). The hypothesis is that, if learners perform the same task several times, their performance on later sessions will improve in complexity, accuracy, and fluency.

To date, a number of studies have been carried in the literature to examine the truth of the above hypothesis (Ahmadian \& Tavakoli, 2011; Bygate, 1996, 2001; Gass et al. 1999; Lynch \& McLean, 2000). For instance, Gass et al.'s (1999) results indicated that task repetition would lead to greater overall proficiency. Further, it resulted in greater fluent language production, an expectable finding given the suggestion that fluency is a context-dependent construct (Riggenbach, 1991). Learners' familiarity with the content and context of a particular task through performing it earlier allows them to be more productively fluent in their subsequent performances. Lynch and McLean (2000) found that task repetition would advantage both linguistic accuracy and fluency. Finally, Bygate (2001) reported that task repetition improved not only his participants' fluency but also their use of complex structures.

Of the studies on task repetition, the most interesting one is Ahmadian and Tavakoli (2011) who aimed to investigate the effects the simultaneous use of both time factors (i.e., time planning and task repetition) on task performance. Their results showed that the simultaneous use of on-line planning and task repetition would advantage all three aspects of linguistic performance. This finding is of importance especially when we consider the fact that careful on-line planning only lets the participants enhance their accuracy and complexity, but not their fluency. In fact, such planning resulted in a statistically significant of dysfluency which was not characteristic of the participants' general language production abilities. Ahmadian and Tavakoli (ibid.) attribute this to the hypothesis that careful on-line planning let the participants "draw on their rule-based system [which] .... acts upon explicit linguistic knowledge retrieved from long-term memory" (p. 54). According to the authors, learners are able to do so at the expense that they "cannot process meaning appropriately and thus the rate 
of speech (fluency) decreases significantly” (p. 54). The dysfluency, however, was overcome, and even more significantly fluent language was produced, when the participants were allowed to repeat the same task since in task repetition they the participants would oversee "processing, retrieval, and utilization of information for performing the same task" (p. 55)

In the previous section, we gave reference to Ortega (1999) who reported that her participants were able to extend their interlanguage competence as a result of being given the opportunity to pre-plan their task performance by focusing their attention on new structures. The same holds true of task repetition as well and evidence on this proposition has been provided by Hawkes (in press). Further, the participants in Hawkes' study (ibid.) benefited from pronunciation corrections (either self- or peer-correction) when they were allowed to repeat the same task. Such findings show the significance of task repetition, particularly as post-task activities by which learners can divert their attentional resources from a preoccupation with meaning (as it has been relatively satisfied in earlier task performances) towards an opportunity to develop their knowledge of L2 formal aspects.

\section{Information Distribution}

One task-inherent factor that has stimulated a great deal of interest among task researchers concerns the way that task information is distributed to the participating parties performing a particular task. Long (1989) makes a distinction between one-way and two-way distribution of task information. One-way distribution requires that all the task information be allotted to only one learner who then communicates it to other task parties. In two-way information, on the other hand, the task information is distributed to all members who are then asked to share and integrate it through pair or group work.

Abundant research has been undertaken in the literature to see whether differences in the ways task information is distributed (i.e., one-way versus two-way information distribution) have significant effects on learners’ task performance (e.g., Fernández-García, 2007; Gass \& Varonis, 1985). For example, Gass and Varonis, (1985) had a group of language learner perform a picture-drawing task (one-way information distribution) and a problem-solving task (two-way information distribution). Their results indicated that no difference in the amount of negotiation was found between the two tasks. This finding is supported by Fernández-García (2007) who claims that learners performing two-way tasks compensate for the lack of shared task background (which is usually a characteristic feature of two-way information gap tasks) by continuous formation of questions, predictions, and inferences based upon interactive negotiation with one another. Further, Fernández-García’s (ibid.) participants were able to provide each other with models of the L2 system through giving feedback, an opportunity that is inconceivable with respect to tasks involving one-way distribution of information. All these advantages of two-way tasks can hypothetically advantage an L2 learner's performance on a task by letting him/her put the responsibility of some meaning handling on the shoulders of his/her task partners. By doing so, the learner has the opportunity to direct his/her cognitive resources to more formal aspects of the L2, resulting in the oral production of more complex, accurate, and fluent language. 


\section{Task Structure}

Another task-inherent factor that is assumed to play a role in learners' linguistic performance on a task is task structure. As defined here, task structure refers to the degree to which "the sequence of the actions [in a task] is predictable and follows a fairly necessary path" (Skehan \& Foster, 1999, p. 104). For example, according Skehan and Foster, to eat in a restaurant follows a predicable sequence of actions which, for example, includes ordering food before it can be served (ibid., p. 104). However, a situation like golfing usually does not follow a tight sequence of actions and is therefore relatively unstructured.

Skehan and Foster's (ibid.) findings showed that when the participants in their study were to perform a task based a situation with clearer inherent sequential structure their language production was more fluent. Skehan and Foster ascribed the participants' fluency to the hypothesis that they felt less need to engage in a great deal of mistake repair as a result of their familiarity with the macrostructure of the task. On the other hand, Skehan and Foster's results demonstrated that task structure advantaged the participants' linguistic accuracy only when it was accompanied with pre-task-planning. Finally, no effects of task structure on complexity were observed in their study in that both structured and unstructured task resulted in the same mean complexity score on the part of the participants.

Interesting results were also obtained by Tavakoli and Foster (2008) who found that performing a tightly structured task advantaged all the three aspects of linguistic performance. The participants who were asked to narrate a story based upon a series of pictures depicting the theme of Picnic (tight task structure) had higher mean scores for complexity, accuracy, and fluency than those narrating a story based on the theme of Walkman (loose task structure). This finding is interesting because it shows that language learners can, to some extent, overcome their cognitive limitations and pay attention to different aspects of their performance while doing a language task if the task is structured in that it involves predictable sequences of actions. Tavakoli and Foster's (ibid.) participants who were required to narrate the Walkman storyline indicated a trade-off between their accuracy on one hand and their fluency and complexity on the other hand. This could be ascribed to the unpredictability of task structure which forces learners to try to figure out what is to come next in the flow of information.

As it is clear, the findings obtained by Tavakoli and Foster (2008) are in partial contradiction to those obtained by Skehan and Foster (ibid.) and such contradiction requires task researchers to carry out further studies to be able to reach more firm conclusions regarding the effects that task structure have on learners' task performance. More interesting is that question of whether this partial contradiction can be explained by differences in the themes of the tasks employed in these two research studies.

\section{Here-and-Now versus There-and-Then Conditions}

Another task-inherent factor that is believed to affect task performance concerns temporal conditions under which a narrative task is performed. That is, are learners required to narrate a story as if it is happening Here-and-Now or are they required to narrate the story in a 
There-and-Then condition? In the former task performance context, the learners narrate a story in the present tense, while in the latter task performance context, the learners narrate the story in the past tense.

Interest in the effects of Here-and-Now versus There-and-then conditions on narrative task performance finds its origin from research findings in L1 and L2 which state that "displaced, past time reference is more complex and therefore appears later than present, context-supported reference" (Gilabert, 2007, p. 51). In the same way, TBLT researchers hypothesize that "tasks in the There-and-Then are more cognitively demanding than tasks performed in the Here-and-Now, with specific consequences for production” (ibid, p. 51). This hypothesis has been supported by, for example, Gilabert (2007), Rahimpour (1997), and Robinson, (1995). Gilabert (2007) reported that, though increasing task complexity along the Here-and-Now variable decreases learners' fluency, it enhances their linguistic accuracy when performing a task. Similarly, Rahimpour's (1997) participants were less fluent in their performance on a There-and-Then task and they also produced more error-free units which are an indication of more linguistic accuracy. However, his participants were not influenced by whether they were required to perform the task as if it is occurring in the present/past as far as their structural and lexical complexity were concerned. This last finding is in partial contrast to Robinson's (1995) findings whose study showed that displaced past time reference (e.g., There-and-Then condition) resulted in more lexical complexity than present time reference (e.g., Here-and-Now condition). Therefore, again, it seems that more investigations should be carried out to be able to make firm conclusions as to what aspects of linguistic performance are affected by changes in the temporal conditions under which a particular task is to be performed.

\section{Individual Differences}

Despite the rich literature on the role of individual differences (IDs) in L2 learning and use, only a few studies have been carried out to see whether these findings are generalizable to L2 learners' task performance. However, even these few studies provide strong evidence that IDs play a significant role in performance on L2 pedagogical tasks (Albert \& Kormos, 2011; Dewaele \& Furnham, 2000; Dörnyei \& Kormos 2000). For example, Albert and Kormos (2011) showed that creativity plays an important role in language learners' task performance. Further, their results showed the role of creativity in task performance is more complex than is assumed since learners' with overall high scores on the measure of creativity used in the study performed the same task in different ways. As a matter of fact, Albert and Kormos (ibid.) traced no significant correlation between the participants' total creativity scores and different aspects of task performance. Albert and Kormos (ibid.) attributed this to the multi-dimensional nature of individual creativity and contended that two separate dimensions of individual creativity (i.e., originality and creative fluency) are of paramount importance as far as learners' task performance is concerned. Albert and Kormos (ibid.) give reference to Baer (1993) when they define these two dimensions of creativity as the following:

- originality: the ability to produce unusual ideas

- creative fluency: the ability to produce a large number of ideas (p. 76). 
As mentioned above, the effects of these two dimensions of creativity on task performance are not monolithic in the sense that each dimension influences task performance in its own particular way. For instance, Albert and Kormos (ibid.) found that the number of words produced by the participants had a significant positive correlation with their creative fluency and a significant negative correlation with creative originality.

To date, the most inclusive study which has investigated the role of a number of ID factors (both affective and sociodynamic) in task performance and engagement has been Dörnyei and Kormos (2000). They tried to find out whether willingness to communicate (WTC), motivation, attitude, anxiety, linguistic self-confidence, and L2 proficiency could predict the degree to which the participants engaged in a task and whether their performance was affected by these IDs. The tasks employed in their study were two alternative versions of an oral argumentative task which involved "an interactive problem-solving activity, aimed at eliciting arguments concerning everyday school matters” (p. 282). Dörnyei and Kormos’ (ibid.) results indicated that participants with higher degrees of WTC took more turns during the task-based oral interaction. This can be explained by the fact that learners with stronger desires to communicate in the L2 (i.e., with higher degrees of WTC) are more willing to initiate and re-initiate conversations in the L2. Also, it was found that situation-specific dimensions of L2 motivation (e.g., attitudes towards the English course, attitudes towards the task and linguistic self-confidence) and learners' perceived linguistic self-confidence had significant positive correlations with the participants' performance on the criterion tasks whereas the same positive correlations were not observed with respect to more general motivational orientations.

Surprisingly, even though it is expected that the opposite holds true, Dörnyei and Kormos' (ibid.) found that there was a negative correlation between the number of words produced by the participants to complete the tasks and their levels of L2 proficiency. The authors attribute this unexpected finding to the hypothesis that the more proficient L2 learners in the study "were able to express their messages in a more concise and to-the-point manner, thereby needing to say less while completing the argumentative tasks” (p. 290).

\section{Designing Task-Based Syllabi}

Regardless of what they consider as the core unit for designing a language teaching syllabus (e.g., lexis, structure, topic, or task), syllabus developers should take two considerations into account. The first consideration relates to the question of what criteria are employed for the selection of items that comprise a particular language teaching syllabus. As far as the development of a task-based syllabus is concerned, the selection criteria for inclusion pedagogical tasks in the syllabus are based on an analysis of target tasks that particular groups of learners need to master for real-world communication purposes (Ellis, 2003; Long, 1985).

On the other hand, the second consideration has to do with the criteria that are employed in a particular task-based program to determine the order or sequence in which pedagogical tasks selected are presented to learners. In contrast to more formal approaches to language teaching, teachers following TBLT principles do not sequence classroom activities (i.e., tasks) in terms 
of linguistic features. Rather, tasks are graded or sequenced according to a number of factors (Robinson, 2001) which affect the complexity of pedagogical tasks or the difficulty with which such tasks are performed and processed by language learners. Some of these factors, and empirical studies carried out to determine their differential effects, were reviewed in this study. It should be reminded that none of these factors alone predicts task complexity or difficulty (ibid.). Rather, their combinatory effects and their interactions specify the complexity/difficulty of a particular task.

\section{Conclusion}

Undoubtedly, the construct of task will continue to attract L2 teachers' and researchers' focus in years to come and this is not surprising given the fact that it has posed promising frontiers to language teachers and researchers alike. However, both of these professional strata should devote time and effort to investigate the role of factors that play relatively significant roles in learners' task performance, a necessity that has been already given impetus within research and practical circles, as shown by the present review study. It is hoped that future studies would shed more light on mechanisms that are involved in learners' ability to perform pedagogical tasks.

\section{References}

Ahmadian, M. J., \& Tavakoli, M. (2011). The effects of simultaneous use of careful online planning and task repetition on accuracy, complexity, and fluency in EFL learners' oral production. Language Teaching Research, 15, 35-59.

Albert, A., \& Kormos, J. (2011). Creativity and narrative task performance: An exploratory study. Language Learning, $61 \quad$ (Supplement $\quad 1$ ), http://dx.doi.org/10.1111/j.1467-9922.2011.00643.x

Anderson, J. R. (1995). Learning and memory: An integrated Approach. New York: Wiley.

Baer, J. (1993). Creativity and divergent thinking: A task specific approach. Hillsdale, NJ: Erlbaum.

Bygate, M. (1996). Effect of task repetition: Appraising the development of second language learners. In J. Willis \& D. Willis (Eds.), Challenge and change in language teaching (pp. 136-46). Oxford: Heinemann.

Bygate, M. (2001). Effects of task repetition on the structure and control of oral language. In M. Bygate, P. Skehan, \& M. Swain (Eds.), Researching pedagogic tasks, second language learning, teaching and testing (pp. 23-48). Harlow: Longman.

Crookes, G. (1989). Planning and interlanguage variation. Studies in Second Language Acquisition, 11, 183-99. http://dx.doi.org/10.1017/S0272263100008391

Dewaele, J.-M., \& Furnham, A. (2000). Personality and speech production: A pilot study of second language learners. Personality and Individual Differences, 28, 355-365. http://dx.doi.org/10.1016/S0191-8869(99)00106-3 
Dörnyei, Z., \& Kormos, J. (2000). The role of individual and social variables in oral task performance. Language Teaching Research, 4, 275-300.

Ellis, R. (1987). Interlanguage variability in narrative discourse: Style shifting and use of the past tense. Studies in Second Language Acquisition, 9, 1-20. http://dx.doi.org/10.1017/S0272263100006483

Ellis, R. (2003). Designing a task-based syllabus. RELC Journal, 34, 64-81. http://dx.doi.org/10.1177/003368820303400105

Ellis, R. (2009). The differential effects of three types of task planning on the fluency, complexity, and accuracy in L2 oral production. Applied Linguistics, 30, 474-509. http://dx.doi.org/10.1093/applin/amp042

Fernández-García, M. (2007). Tasks, Negotiation, and L2 Learning in a Foreign Language Context. In M. P. Garcia-Mayo (Ed.), Investigating tasks in formal language learning (pp. 69-90). Clevedon: Multilingual Matters.

Foster, P., \& Skehan, P. (1996). The influence of planning and task type on second language performance. Studies in Second Language Acquisition. 18, 299-323. http://dx.doi.org/10.1017/S0272263100015047

Gass, S. M., \& Varonis, E. M. (1985). Task variation and nonnative/non-native negotiation of meaning. In S.M. Gass and C.G. Madden (Eds.), Input in Second Language Acquisition (pp. 149-161). Rowley, MA: Newbury House.

Gass, S. M., Mackey, A., Fernandez, M., \& Alvarez-Torres, M. (1999). The effects of task repetition on linguistic output. Language Learning, 49, 549-80. http://dx.doi.org/10.1111/0023-8333.00102

Gilabert, R. (2007). The simultaneous manipulation of task complexity along planning time and [+ / Here-and-Now]: effects on L2 oral production. In M. P. Garcia-Mayo (Ed.), Investigating tasks in formal language learning (pp. 44-68). Clevedon: Multilingual Matters.

Guara-Tavares, M. G. (2008). Pre-task planning, working memory capacity and L2 speech performance. Unpublished Doctoral Thesis, Universidade Federal de Santa Catarina, Brazil.

Hawkes, M. L. (in press). Using task repetition to direct learner attention and focus on form. ELT Journal.

Kawauchi, C. (2005). The effects of strategic planning on the oral narratives of learners with low and high intermediate proficiency. In R. Ellis (Ed.), Planning and task performance in second language. Amsterdam: John Benjamins.

Long, M. (1985). A role for instruction in second language acquisition. In M. Pienemann \& K. Hyltenstam (Eds.), Modelling and assessing second language acquisition (pp. 77-99). Clevedon: Multilingual Matters. 
Long, M. H. (1989). Task, group and task-group interactions. In S. Anivan (Ed.), Language Teaching Methodology for the Nineties (pp. 31-50). Singapore: SEAMEO Regional Language Centre.

Lynch, T., \& Maclean, J. (2000). Exploring the benefits of task repetition and recycling for classroom language learning. Language Teaching Research, 4, 221-50.

Ortega, L. (1999). Planning and focus on form in L2 oral performance. Studies in Second Language Acquisition, 21, 109-148. http://dx.doi.org/10.1017/S0272263199001047

Rahimpour, M. (1997). Task condition, task complexity and variation in L2 discourse. Unpublished PhD dissertation, University of Queensland.

Riggenbach, H. (1991). Toward an understanding of fluency: A microanalysis of nonnative speaker conversations. Discourse Processes, 14, 423-441. http://dx.doi.org/10.1080/01638539109544795

Robinson, P. (1995) Task complexity and second language narrative discourse. Language Learning 45, 99-140. http://dx.doi.org/10.1111/j.1467-1770.1995.tb00964.x

Robinson, P. (2001). Task complexity, task difficulty, and task production: Exploring Interactions in a componential framework. Applied Linguistics, 22, 27-57. http://dx.doi.org/10.1093/applin/22.1.27

Skehan, P. (1996a). A framework for the implementation of task-based instruction. Applied Linguistics, 17, 38-62. http://dx.doi.org/10.1093/applin/17.1.38

Skehan, P. (1996b). Second-language acquisition research and task-based instruction. In J. Willis \& D. Willis (Eds.), Challenge and change in language teaching (17-30). Oxford: Heinemann.

Skehan, P., \& Foster, P. (1997). The influence of planning and post-task activities on accuracy and complexity in task based learning. Language Teaching Research, 1, 185-211. http://dx.doi.org/10.1177/136216889700100302

Skehan, P., \& Foster, P. (1999). The influence of task structure and processing conditions on narrative retellings. Language Learning, 49, 93-120. http://dx.doi.org/10.1111/1467-9922.00071

Tajima, M. (2003). The effects of planning on oral performance of Japanese as a foreign language. Unpublished Dissertation, Purdue University.

Tavakoli, P., \& Foster, P. (2008). Task design and second language performance. The effect of narrative type on learner output. Language Learning, 58, 439-473. http://dx.doi.org/10.1111/j.1467-9922.2008.00446.x

Yuan, Y., \& Ellis, R. (2003). The effects of pre-task planning and on-line planning on fluency, complexity, and accuracy in L2 monologicoral production. Applied Linguistics, 24, 1-27. http://dx.doi.org/10.1093/applin/24.1.1 


\section{Copyright Disclaimer}

Copyright reserved by the author(s).

This article is an open-access article distributed under the terms and conditions of the Creative Commons Attribution license (http://creativecommons.org/licenses/by/3.0/). 